\title{
Ankle and foot surgery: from arthrodesis to arthroplasty, three dimensional printing, sensors, artificial intelligence, machine learning technology, digital twins, and cell therapy
}

\author{
Philippe Hernigou ${ }^{1} \cdot$ Marius M. Scarlat $^{2}$
}

Published online: 26 August 2021

C SICOT aisbl 2021

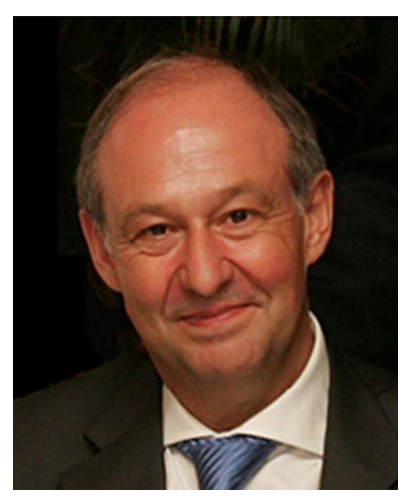

Philippe Hernigou

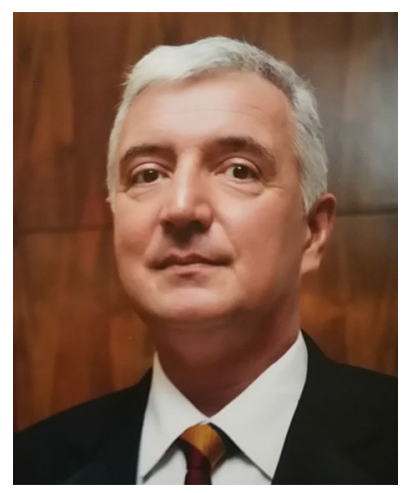

Marius M. Scarlat

Marius M. Scarlat

mscarlat@gmail.com

1 Henri Mondor Hospital, University Paris, Créteil, France

2 Clinique St. Michel, Groupe ELSAN, Toulon, France

For the first time, digital twins have entered the history of orthopaedics with this special issue in International Orthopaedics on Foot and Ankle surgery [1]. After the augmented reality and virtual reality, the virtual environment was introduced in 2002 by Grieves [2] and was named as "digital twin" in 2010 by Vickers [3] of NASA. This emerging technology developed for space can now be used in orthopaedics via the CAD Catia ${ }^{\mathrm{TM}}$ (Dassault system) to evaluate movements, axes of joints, and implants. A human digital twin (DT) is the digital image of a physical human (the real twin or physical twin). This "nonliving entity" enables patient data to be transmitted between the physical world and the virtual world, as proposed by Hernigou and Ferré [1] for ankle surgery. The ankle was a target for this new technology. Anatomically, the ankle and the foot form a functional unit that allows plantigrade and bipedal ambulation with some particularities in specific sports as karate in this Olympic Games Year when studied by Cazeau et al. [4]. The anatomical centre of the ankle motion is the talus; the talus's articular surface was schematically considered a truncated cone with the apex directed medially. In reality, the anatomy of the ankle is much more complex, and each individual has a personalized axis of motion. A particular approach using complicated software is proposed by Hernigou et al. [1]: digital twins, artificial intelligence, and machine learning technology were used to identify the motion axis of the tibiotalar joint. The study showed that although the articular surfaces of the talus can be considered as an asymmetric trochlea with several radii of curvature, it is possible to obtain details on the axis of motion for each individual before surgery and to report this axis in a geodesic reference which will make possible to use robotics for ankle prostheses in the next future.

Ankle and foot arthrodesis has been proposed for over 100 years [5] to treat neuromuscular pathologies. For a very long time, the most frequent indication was the treatment of poliomyelitis. With the development of new techniques 
and the success of arthrodesis, the indications have extended to post-traumatic osteoarthritis other neurological diseases such as Charcot arthropathy [6], the correction of adultacquired flatfoot deformity [7-9], osteonecrosis of the talus, and sequelae of cerebral palsy. The frequency of post-traumatic ankle arthrodesis has increased in recent years due to sports practice; however, sports activity level [10] following an ankle fusion is decreased, and many patients will not return to their pre-injury level of activity. The clubfoot pathology rarely recurs in adulthood when corrected in childhood with the classical Ponseti technique $[11,12]$ or with a new technology [13] with sensors integrated in the brace. However, a neglected clubfoot [14] or persistent deformities with arthritic pain may require further arthrodesis during adulthood.

The immediate functional result of arthrodesis is usually good. Ankle arthrodesis suppresses pain and allows patients to walk throughout the day without difficulty. The limit is the practice of stairs when the steps are high; another limitation is walking on rough ground. While there is only one bone above the talus, there are twenty-six bones below, and any misalignment of the position of arthrodesis can increase wear of the cartilage on these twenty-six distal bones and can lead to dysfunction of the foot and degradation of the underlying joints. In the long-term, arthrodesis is not without problems because it causes at least a stiffening of the hindfoot joints, the other joints of the foot, and sometimes a degenerative degradation that obliges to extend the arthrodesis [15].

The first total ankle arthroplasty was performed in 1970 by Lord and Marrott in France [16]. The tibial component had a long stem (similar to a femoral prosthesis), coupled with a polyethylene talar component that replaced the body of the talus. If arthrodesis remained during the twentieth century the standard treatment for ankle pathology, total ankle arthroplasty has become a possible treatment, thanks to the progress made in implants as well as in surgical technique. The advantage of replacing the ankle using a prosthesis is the preservation of movement and function. This may also result in the protection of other joints. There are two different designs concerning bearing surfaces: fixed bearings and mobile bearings. While fixed-bearing ankles have one articulation between tibial and talar components, mobile-bearing ankles have a moving polyethylene bearing that separates the convex talar component from the flat tibial component.

The relative benefits of total ankle arthroplasty (TAA) and ankle fusion continue to be among the most debated foot and ankle surgery. Treatment selection is crucial for improving the quality of life [15]. Unfortunately, there are some problems associated with ankle arthrodesis, such as the possibility of degenerative changes in adjacent joints and gait abnormality due to a loss of motion; and there are also some problems associated with TAA, such as loosening and revision [17-19]. Before arthroplasty or arthrodesis additional surgeries are usually necessary in case of malalignment or ligament instability. An osteotomy of the first metatarsal [20, 21] or another technique [22] may be required in the event of malposition of the hallux. A malunion of a calcaneus fracture $[23,24]$ is a common cause of rearfoot misalignment, and a valgus osteotomy of the calcaneus $[25,26]$ may be useful to correct a post-traumatic varus. The Achilles tendon is a determinant of ankle function after an arthroplasty; due to the potential alteration [27] during an arthroplasty, a secondary reconstruction [28] of chronic Achilles' tendon rupture is sometimes necessary.

Foot and ankle surgery has benefited from technological advances obtained in other joints. Emerging technologies for pain prevention and prevention of the complex regional pain syndrome after foot and ankle surgery are available with vitamin C [29] as for knee surgery [30]. Determining the optimal combination of pain medication remains a challenge, particularly in outpatient surgery, with some difficulties detecting an early opioid-induced respiratory depression when the patient is at home [31]. The use of tranexamic acid [32] has been proposed to decrease peri-operative bleeding in ambulatory foot and ankle surgery, but results are not successful at this moment. The recent pandemic of the COVID19 has needed to optimize hospital admissions and healthcare resources. Two studies have examined the outcomes of outpatient surgery, one in adults [33] with a protocol for the treatment of acute closed ankle fractures, another in adults for ankle arthroplasties [34], and one in children [35] for a percutaneous Achilles tenotomy under local anesthetic in clubfoot. This outpatient management was associated with surgery success without increasing risks of rates of hospital readmissions.

Among other promising innovations adapted from other orthopedic subspecialties are 3D printing, biologics. The recent use of 3D printing in orthopedics has been the generation of knee patient-specific implants (PSI), that are now available for ankle arthroplasty [36]. In foot and ankle surgery, 3D printing can be used for printing customized talus implants when the total collapse does not allow to perform cuts for a standard total ankle arthroplasty. When a total ankle arthroplasty is proposed for talus necrosis with the extensive collapse of the entire talar body, whether for arthrodesis or prosthesis, the technical challenges are considerable since it is difficult to obtain a tibio-calcaneal arthrodesis or to implant a conventional ankle prosthesis when there is not enough bone left to make satisfactory bone cuts. The talar prosthesis [37] obtained with three-dimension printing (obtained from the shape of the talus from the contralateral side) for total talar replacement may be one solution.

Concerning biologics progress, cell therapy [38] is a possibility for osteonecrosis or other pathology as treatment of 
recalcitrant Achilles' tendinopathy [39]. Foot and ankle pathologies include osteoarthritis and primary arthritis as well as post-traumatic pathology, but also necrosis of the talus. The prevalence of non-traumatic osteonecrosis is lower for the ankle than for the hip or knee. The treatment of talus necrosis, whether post-traumatic [38] or primary, due to corticosteroid intake or sickle cell disease [40] remains a challenge at early stages, particularly in children. Ankle osteonecrosis may occur in childhood leukemia survivors [41] after corticosteroids treatment. Using percutaneous cell therapy in this young population is a possibility. Hernigou et al. [41] performed autologous mesenchymal stem cells implantation with aspiration and concentration of the iliac crest bone marrow. For talus chondral defect or ankle osteoarthritis, scaffolds, subchondral, or intra-articular injections of fresh autologous bone marrow concentrate, regenerative cells are possible as for the knee [42]; autologous chondrocyte implantation with spheroids in the treatment of significant chondral defects are another possibility [43] for the future.

\section{References}

1. Hernigou P, Olejnik R, Safar A, Martinov S, Hernigou J, Ferre B (2021) Digital twins, artificial intelligence, and machine learning technology to identify a real personalized motion axis of the tibiotalar joint for robotics in total ankle arthroplasty. Int Orthop.https://doi.org/10.1007/s00264-021-05175-2

2. Grieves M (2019) 'Virtually intelligent product systems: Digital and physical twins. In: complex systems engineering: theory and practice. American Institute of Aeronautics and Astronautics, pp 175-200

3. Piascik R, Vickers J, Lowry D, et al (2010) 'Technology area 12: materials, structures, mechanical systems, and manufacturing road map.

4. Cazeau C, Courtonne C, Delacroix S, Lescure Y, Piat C, Stiglitz Y (2021) Biomechanical study comparing the energy cost of human bipedalism versus zenkutsu-dachi stepping of a karateka. Int Orthop.https://doi.org/10.1007/s00264-021-05142-x

5. Cook AG, Stern WG, Ryerson EW (1923) Report of the commission appointed by the American Orthopedic Association for the study of stabilizing operations on the foot. J Bone Joint Surg 5:135-140

6. El-Mowafi H, Elghazy MA, Kandil YR, Ali S, El-Hawary A, Abulsaad MS (2021) Charcot arthropathy of foot and ankle: radiographic and clinical patterns with related outcomes. Int Orthop.https://doi.org/10.1007/s00264-021-05082-6

7. Ferreira GF, Nava N, Durigon TS, Dos Santos TF, Pereira Filho MV (2021) Double hindfoot arthrodesis using a single-incision medial approach in the correction of adult-acquired flatfoot deformity: a case series. Int Orthop.https://doi.org/10.1007/ s00264-021-05057-7

8. Fadle AA, El-Adly W, Attia AK, Mohamed MM, Mohamadean A, Osman AE (2021) Double versus triple arthrodesis for adultacquired flatfoot deformity due to stage III posterior tibial tendon insufficiency: a prospective comparative study of two cohorts. Int Orthop.https://doi.org/10.1007/s00264-021-05041-1
9. Tahririan MA, Ramtin S, Taheri P (2021) Functional and radiographic comparison of subtalar arthroereisis and lateral calcaneal lengthening in the surgical treatment of flexible flatfoot in children. Int Orthop.https://doi.org/10.1007/ s00264-020-04899-x

10. Hanna M, Whicker EA, Traub B, Allam E, Labib SA (2021) Sport activity levels following ankle fusion. Int Orthop.https://doi.org/ 10.1007/s00264-021-05100-7

11. Addosooki A, Tammam H, Morsy AF, Marzouq A, Ahmed EH, Ahmed AM, Said E. (2021) Correlation of radiographic parameters with clinical correction in idiopathic congenital talipes equinovarus undergoing Ponseti treatment. Int Orthop.https://doi.org/ 10.1007/s00264-021-05138-7

12. Al-Mohrej OA, Alshaalan FN, Alhussainan TS (2021) Is the modified Ponseti method effective in treating atypical and complex clubfoot? A systematic review. Int Orthop. https://doi.org/10. 1007/s00264-021-05092-4

13. Aroojis A, Pandey T, Dusa A, Krishnan AG, Ghyar R, Ravi B (2021) Development of a functional prototype of a SMART (sensor-integrated for monitoring and remote tracking) foot abduction brace for clubfoot treatment: a pre-clinical evaluation. Int Orthop.https://doi.org/10.1007/s00264-021-05042-0

14. Pigeolet M, Imam S, Ninulescu GC, Kabir S, Smeesters PR, Mahmud H. (2021) Evaluation of a surgical treatment algorithm for neglected clubfoot in low-resource settings. Int Orthop. https:// doi.org/10.1007/s00264-021-05058-6

15. Fanelli D, Mercurio M, Castioni D, Sanzo V, Gasparini G, Galasso O. (2021) End-stage ankle osteoarthritis: arthroplasty offers better quality of life than arthrodesis with similar complication and reoperation rates-an updated meta-analysis of comparative studies. Int Orthop.https://doi.org/10.1007/s00264-021-05053-x

16. Lord G, Marotte JH (1973) Total ankle prosthesis. Technic and 1st results. Apropos of 12 cases. Rev Chir Orthop Reparatrice Appar Mot 59:139-151

17. Clifton LJ, Kingman A, Rushton PRP, Murty A, Kakwani R, Coorsh J, Townshend DN (2021) The Hintegra total ankle replacement: survivorship, failure modes and patient reported outcomes in seventy consecutive cases with a minimum five year follow-up. Int Orthop.https://doi.org/10.1007/s00264-021-05071-9

18. Bianchi A, Martinelli N, Caboni E, Raggi G, Manfroni F, Sansone V (2021) Long-term follow-up of Bologna-Oxford (BOX) total ankle arthroplasty. Int Orthop 45:1223-1231. https://doi.org/10. 1007/s00264-021-05033-1

19. Mahmoud K, Metikala S, O'Connor KM, Farber DC (2021) Adverse events related to total ankle replacement devices: an analysis of reports to the United States Food and Drug Administration. Int Orthop.https://doi.org/10.1007/s00264-021-04972-z

20. Choi JY, Kim BH, Suh JS (2021) A prospective study to compare the operative outcomes of minimally invasive proximal and distal chevron metatarsal osteotomy for moderate-to-severe hallux valgus deformity. Int Orthop.https://doi.org/10.1007/ s00264-021-05106-1

21. Lee J, Lee HS, Jeong J-J, Seo DK, Kee T, So S, Choi YR (2021) Distal chevron metatarsal osteotomy is a viable treatment option for hallux valgus with metatarsus adductus-multicentre retrospective study. Int Orthop.https://doi.org/10.1007/ s00264-021-05117-y

22. Piat C, Cazeau C, Stiglitz Y (2021) Post-operative hallux varus: a review of treatment methods. Int Orthop.https://doi.org/10.1007/ s00264-021-05143-w

23. Xu H, Hou R, Ju J, Liu Y, Chen L (2021) Articular calcaneal fractures: open or minimally invasive surgery, when the medial wall reduction is obtained percutaneously from the lateral side. Int Orthop.https://doi.org/10.1007/s00264-021-05164-5

24. Zhang Y, Weng Q, Gu Y, Chen J, Yang Y (2021) Calcaneal fractures: 3D-printing model to assist spatial weaving of percutaneous 
screws versus conventional open fixation-a retrospective cohort study. Int Orthop.https://doi.org/10.1007/s00264-021-05094-2

25. Guan X, Xiang D, Hu Y, Jiang G, Yu B, Wang B. (2021) Malunited calcaneal fracture: the role and technique of osteotomy-a systematic review. Int Orthop.https://doi.org/10.1007/ s00264-021-05130-1

26. González-Martín D, Herrera-Pérez M, Ojeda-Jiménez J, RendónDíaz D, Valderrabano V, Pais-Brito JL (2021) "Safe incision" in calcaneal sliding osteotomies reduces the incidence of sural nerve injury. Int Orthop.https://doi.org/10.1007/s00264-021-05109-y

27. Arshad Z, Lau EJS, Leow SH, Bhatia M (2021) Management of chronic Achilles ruptures: a scoping review. Int Orthop.https:// doi.org/10.1007/s00264-021-05102-5

28. Fischer S, Kutscher R, Gramlich Y, Klug A, Hoffmann R, Manegold S (2021) Secondary reconstruction of chronic Achilles tendon rupture: flexor hallucis longus transfer versus plantaris longus augmentation. Int Orthop.https://doi.org/10.1007/ s00264-021-05128-9

29. Hernigou J, Labadens A, Ghistelinck B, Bui Quoc E, Maes R, Bhogal H, Callewier A, Bath O, Chahidi E, Safar A (2021) Vitamin $\mathrm{C}$ prevention of complex regional pain syndrome after foot and ankle surgery: a prospective randomized study of three hundred and twenty nine patients. Int Orthop.https://doi.org/10.1007/ s00264-021-05159-2

30. Hernigou J, Valcarenghi J, Callewier A, Sohm L, Decottenier V, Ledoux A, Kyriakidis T, Bath O (2021) Correction to: prospective randomized study of the vitamin $\mathrm{C}$ effect on pain and complex pain regional syndrome after total knee arthroplasty. Int Orthop 45:1385. https://doi.org/10.1007/s00264-021-04981-y

31 Hernigou P (2021) The seductive poppy: are orthopaedists able to prevent a second wave of the opium pandemic with outpatient surgery?: commentary on an article by Nathan H. Varady, SB, et al.: "opioid use following inpatient versus outpatient total joint arthroplasty." J Bone Joint Surg Am 103:e23. https://doi.org/10. 2106/JBJS.20.02106

32. B H PP, Diskina D, Lin HM, Vulcano E, Lai YH (2021) Use of tranexamic acid does not influence perioperative outcomes in ambulatory foot and ankle surgery-a prospective triple blinded randomized controlled trial. Int Orthop.https://doi.org/10.1007/ s00264-021-05131-0

33. Bullock TS, Gutierrez-Naranjo JM, DelBello RG, DelBello RG, Karia RA, Zelle BA (2020) Outpatient surgery in patients with ankle fractures minimises hospital admissions and utilisation of healthcare resources. Int Orthop.https://doi.org/10.1007/ s00264-020-04768-7

34. Sadoun M, Hardy A, Cladière V, Guichard L, Bauer T, Stiglitz Y (2021) Outpatient total ankle replacement. Int Orthop.https://doi. org/10.1007/s00264-021-05140-z
35. Barkham B, McNally T, Russell A, Bridgens A, Gelfer Y (2021) Percutaneous Achilles tenotomy under local anaesthetic in the clubfoot clinic was safe during the COVID-19 pandemic, for both children and parents. Int Orthop.https://doi.org/10.1007/ s00264-021-05119-w

36. Wang Q, Zhang N, Guo W, Wang W, Zhang Q (2021) Patient-specific instrumentation (PSI) in total ankle arthroplasty: a systematic review. Int Orthop.https://doi.org/10.1007/s00264-021-05145-8

37. Mu MD, Yang QD, Chen W, Tao X, Zhang CK, Zhang X, Xie MM, Tang KL (2021) Three dimension printing talar prostheses for total replacement in talar necrosis and collapse. Int Orthop.https://doi.org/10.1007/s00264-021-04992-9

38. Hernigou P, Dubory A, Flouzat Lachaniette CH, Khaled I, Chevallier N, Rouard H (2018) Stem cell therapy in early post-traumatic talus osteonecrosis. Int Orthop 42:2949-2956. https://doi.org/10. 1007/s00264-017-3716-7

39. Thueakthong W, de Cesar Netto C, Garnjanagoonchorn A, Day J, Friedman G, Auster H, Tan E, Schon LC (2021) Outcomes of iliac crest bone marrow aspirate injection for the treatment of recalcitrant Achilles tendinopathy. Int Orthop.https://doi.org/10. 1007/s00264-021-05112-3

40. Hernigou P, Flouzat-Lachaniette $\mathrm{CH}$, Daltro G, Galacteros F (2016) Talar osteonecrosis related to adult sickle cell disease: natural evolution from early to late stages. J Bone Joint Surg Am 98:1113-1121. https://doi.org/10.2106/JBJS.15.01074

41. Hernigou P, Auregan JC, Dubory A, Flouzat Lachaniette CH, Rouard H (2021) Ankle osteonecrosis in fifty-one children and adolescent's leukemia survivors: a prospective randomized study on percutaneous mesenchymal stem cells treatment. Int Orthop.https://doi.org/10.1007/s00264-021-05051-z

42. Hernigou J, Vertongen P, Rasschaert J, Hernigou P (2021) Role of scaffolds, subchondral, intra-articular injections of fresh autologous bone marrow concentrate regenerative cells in treating human knee cartilage lesions: different approaches and different results. Int J Mol Sci 22.https://doi.org/10.3390/ijms22083844

43. Vonk LA, Roël G, Hernigou J, Kaps C, Hernigou P (2021) Role of matrix-associated autologous chondrocyte implantation with spheroids in the treatment of large chondral defects in the knee: a systematic review. Int J Mol Sci 22:7149. https://doi.org/10.3390/ ijms22137149

Publisher's note Springer Nature remains neutral with regard to jurisdictional claims in published maps and institutional affiliations. 